\title{
Comment on "Control of fossil-fuel particulate black carbon and organic matter, possibly the most effective method of slowing global warming" by M. Z. Jacobson
}

\author{
Joyce E. Penner \\ Department of Atmospheric, Oceanic, and Space Sciences, University of Michigan, Ann Arbor, Michigan, USA \\ Received 29 December 2002; revised 19 February 2003; accepted 27 March 2003; published 18 December 2003. \\ INDEX TERMS: 0305 Atmospheric Composition and Structure: Aerosols and particles(0345, 4801); 1620 \\ Global Change: Climate dynamics(3309); 3309 Meteorology and Atmospheric Dynamics: Climatology \\ (1620); 3367 Meteorology and Atmospheric Dynamics: Theoretical modeling; 4215 Oceanography: \\ General: Climate and interannual variability(3309); KEYWORDS: upwelling diffusion model, climate \\ model, black carbon, indirect forcing, forcing, fossil fuel
}

Citation: Penner, J. E., Comment on "Control of fossil-fuel particulate black carbon and organic matter, possibly the most effective method of slowing global warming”' by M. Z. Jacobson, J. Geophys. Res., 108(D24), 4771, doi:10.1029/2002JD003364, 2003.

\section{Introduction}

[1] Jacobson [2002] argued that the relative benefits of fossil-fuel (f.f.) particulate black carbon (BC) plus associated organic matter $(\mathrm{OM})$ reductions are much greater than either $\mathrm{CO}_{2}$ or $\mathrm{CH}_{4}$ reductions in the near term. However, Jacobson's [2002] calculation of the benefits of these reductions over time is not consistent with a model that includes the exchange of heat between the mixed-layer ocean and the deeper ocean. In addition, his model may not have been run long enough to obtain a quasi-steady state temperature change. These considerations raise serious concerns about the adequacy of Jacobson's [2002] calculations. Moreover, he obtains a warming from the combined direct and indirect effects of f.f. $\mathrm{BC}+\mathrm{OM}$ that is inadequately documented. This warming may disagree with the results of published models by the aerosol-climate community. For example, Penner et al. [2003] (which is based on the model published by Chuang et al. [2002]) obtain a forcing for f.f. BC + OM that is not significantly different from zero, whereas Jacobson [2002] has an inferred forcing for f.f. $\mathrm{BC}+\mathrm{OM}$ that is $0.5 \mathrm{Wm}^{-2}$. The model of Lohmann et al. [2000] gives a shortwave forcing for carbonaceous aerosols (the sum of forcing from fossil-fuel $\mathrm{BC}+\mathrm{OM}$ and biomass burning) that is similar to that in the model of Penner et al. [2003].

[2] Hansen et al. [2000] pointed out that our strategy to slow and control global warming, while requiring fossil-fuel conservation measures, should focus on reducing emissions related to air pollution: $\mathrm{CH}_{4}, \mathrm{O}_{3}$ precursors, and $\mathrm{BC}$. The benefits of $\mathrm{BC}$ reduction, however, were evaluated as highly uncertain. Jacobson [2002, paragraph [1]] proposed that "any emission reduction of fossil-fuel (f.f.) particulate BC plus associated organic matter (OM) may slow global warming more than may any emission reduction of $\mathrm{CO}_{2}$ or $\mathrm{CH}_{4}$ for a specific period." This rather general statement must, of course, depend on the specific emission reductions that are proposed. Moreover, it depends on the claim that f.f. $\mathrm{BC}+$

Copyright 2003 by the American Geophysical Union. 0148-0227/03/2002JD003364
OM actually warms the climate rather than cooling it. The scenario that Jacobson [2002] evaluates is a reduction of all emissions of f.f. $\mathrm{BC}+\mathrm{OM}$ and all emissions of anthropogenic $\mathrm{CO}_{2}$ and $\mathrm{CH}_{4}$. Because the lifetime of $\mathrm{BC}+\mathrm{OM}$ in the atmosphere is much shorter than the lifetime of $\mathrm{CH}_{4} \mathrm{Or} \mathrm{CO}_{2}$ in the atmosphere, if $\mathrm{BC}+\mathrm{OM}$ warms, then one might expect more rapid cooling from a total cessation of f.f. $\mathrm{BC}+\mathrm{OM}$ emissions than from a cessation of anthropogenic $\mathrm{CH}_{4}$ or $\mathrm{CO}_{2}$ emissions. As I show below, the specific amount of cooling and the time frame over which cooling takes place as described in Jacobson's [2002] model would benefit from further documentation and assessment. In addition, his calculation that indicates that f.f. $\mathrm{BC}+\mathrm{OM}$ warms appears to disagree with two other models [e.g., Penner et al., 2003; Lohmann et al., 2000] that have published results in the open literature. Here, I examine the assumptions made in this paper and present alternative results.

[3] The questionable assumptions on which the conclusions of this paper rests are the following: (1) The time history of the atmospheric temperature response to a reduction of f.f. $\mathrm{BC}+\mathrm{OM}$ emissions can be quantified using a mixed-layer ocean with a 60-m depth. (2) The time history of the atmospheric temperature response to a reduction of $\mathrm{CO}_{2}$ can be calculated by assuming that the temperature will respond with the same response time as the lifetime for $\mathrm{CO}_{2}$. (3) The steady state results of the climate model can be calculated with calculations of only 6 years duration. (4) The effects of f.f. $\mathrm{BC}+\mathrm{OM}$ emissions warm the climate.

[4] Below, I use the upwelling diffusion model of Hoffert et al. [1980] to examine assumptions 1 and 2, and I examine assumptions 3 and 4 in light of other literature.

\section{Discussion of Assumptions}

2.1. Assumption That the Atmospheric Temperature Response to a Reduction of f.f. BC + OM Emissions Can Be Quantified Using a Mixed-Layer Ocean With a 60-m Depth

[5] The thermal inertia of a 60-m depth ocean can be calculated from $\rho \cdot C_{p} \cdot h_{m}$, where $\rho$ is the density of ocean 
mixed layer, $C_{p}$ is the specific heat, and $h_{m}$ is the mixed layer depth. This is about a factor of 50 less than that of a 3000-m deep ocean. Thus the rate of response of the mixed layer to a change in climate forcing is much faster than that of the full (entire) ocean. Considerations of this fact led several authors, including Jacobson [2002], to ignore the exchange of heat between the mixed layer and the deep ocean [Schneider and Mass, 1975; Burt and Viecelli, 1980], but Hoffert et al. [1980] argue that this term is important in determining the temperature of the mixed layer and lower atmosphere. Hoffert et al. [1980] derive the following equation for the globally averaged atmospheric temperature response to forcing:

$$
\frac{d T_{a}}{d t}=\frac{T_{e q}(t)-T_{a}}{\tau_{r m}}-\frac{1}{h_{m}} \frac{\partial}{\partial t} \int_{0}^{h_{d}} \theta(z, t) d z
$$

where $T_{a}$ is the temperature of the lower atmosphere, $T_{e q}(t)$ is the global average equilibrium temperature for a timedependent forcing, $h_{m}$ is the depth of the ocean mixed layer, and $\theta$ is the global average potential temperature in the deep ocean as a function of depth. $\tau_{r m}$ is the characteristic timescale for radiative equilibrium in the global average ocean mixed layer, which is given by $\rho h_{m} A C p /\left(4 \pi a^{2} B\right)$, where $A$ is the area of the world's oceans, $a$ is the Earth's radius, and $B$ is the slope of the outgoing longwave radiation with surface temperature $\left(\partial F / \partial T_{a}\right)$.

[6] The last term in equation (1) measures the importance of the exchange of heat between the mixed layer and the deep ocean in determining the time-dependent response of the atmospheric temperature to a given forcing. In the study by Hoffert et al. [1980] this term is calculated using an upwelling-diffusion model. This requires specifying a globally averaged upwelling velocity $w$, a parameter $\pi$ specifying the warming rate of the polar sea relative to the mean warming rate of the areally averaged surface ocean, the deep ocean eddy diffusivity $K$, and the depth of the mixed-layer $h_{m}$. In what follows, I have set these parameters to $4 \mathrm{~m} / \mathrm{yr}, 1$, $2000 \mathrm{~m}^{2} / \mathrm{yr}$, and $100 \mathrm{~m}$ (which corresponds to a radiative relaxation time $\tau_{r m}$ of $3.9 \mathrm{yr}$ ), respectively. As shown by Hoffert et al. [1980], the specific time history that one obtains for any given scenario depends on the choice of these parameters. The parameters are often chosen to specifically mimic the results of climate models.

[7] The assumption that Jacobson [2002] makes in ignoring the exchange of energy with the deep ocean temperature is (in energy-balance model parlance) equivalent to estimating the globally averaged temperature from

$$
\frac{d T_{a}}{d t}=\frac{T_{e q}(t)-T_{a}}{\tau_{r m}}
$$

rather than equation (1). The solid black curve in Figure 1 illustrates results obtained solving equation (1) for removal of fossil-fuel $\mathrm{BC}+\mathrm{OM}$ if we assume that the current day forcing for f.f. $\mathrm{BC}+\mathrm{OM}$ is $0.5 \mathrm{Wm}^{-2}$ (a warming) and the climate in year 2000 is at equilibrium. A forcing of about $0.5 \mathrm{Wm}^{-2}$ is required in this model to obtain a temperature change at equilibrium that is consistent with the temperatue

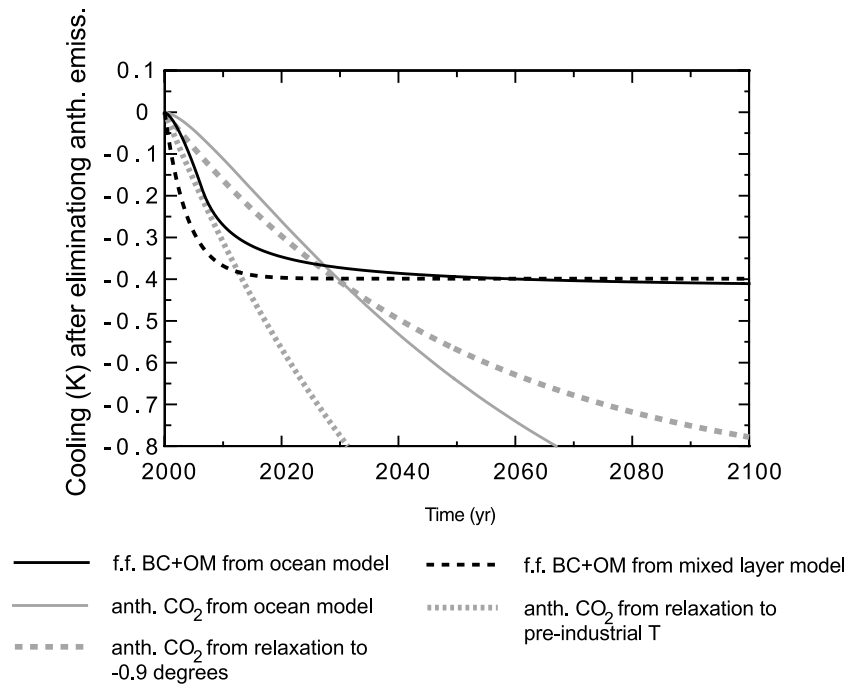

Figure 1. Temperature response to eliminating all f.f. emissions of $\mathrm{BC}+\mathrm{OM}$ from the upwelling-diffusion ocean model (solid black curve) and from a mixed-layer ocean with a response time of 3.9 years, similar to that used by Jacobson [2002] (dashed black curve). The climate forcing associated with present-day f.f. $\mathrm{BC}+\mathrm{OM}$ was assumed to be $0.5 \mathrm{Wm}^{-2}$. Almost no change in temperature would have occurred if the forcing calculated by Penner et al. [2003] for f.f. $\mathrm{BC}+\mathrm{OM}$ had been used. The temperature response to eliminating all anthropogenic emissions of $\mathrm{CO}_{2}$ (assuming a 50 -year lifetime for $\mathrm{CO}_{2}$ ) for the ocean model is given by the solid gray curve. The short-dashed gray curve assumes a 50 -year response time for temperatures using the presentday minus the preindustrial temperatures calculated in the ocean model $\left(1.3^{\circ} \mathrm{C}\right)$, which is consistent with scaling the temperature change for $2 \times \mathrm{CO}_{2}$ by the difference in forcing and assumes a constant climate sensitivity. The long-dashed gray curve shows results similar to those of Jacobson [2002], whose model apparently has a different climate sensitivity for the change in temperature associated with doubling $\mathrm{CO}_{2}$ and for the change in temperature associated with the difference in present-day and preindustrial $\mathrm{CO}_{2}$ concentrations.

change found by Jacobson [2002]. The black dashed curve shows results obtained solving equation (2).

[8] By neglecting mixing with the deep ocean, the temperature response to removal of f.f. $\mathrm{BC}+\mathrm{OM}$ is too fast relative to a model that accounts for this exchange of heat. Using the parameters chosen here, the expected response time for a model that includes mixing with the deep ocean is of order 10 years, consistent with the delayed response to removal of $\mathrm{BC}+\mathrm{OM}$ shown in Figure 1 [e.g., Hansen et al., 1985]. (Had I included the observed increase in greenhouse gases prior to the year 2000 rather than starting the model simulation from a near-equilibrium, the temperature change would have continued to increase before starting its decrease in response to $\mathrm{BC}+\mathrm{OM}$ removal.) The near-instantaneous time response of the dashed black curve relative to that of the solid black curve is caused by the neglect of mixing with the deep ocean. While exchange of heat with the deep ocean is considered 
one of the more uncertain factors in determining the rate of temperature change [e.g., Forest et al., 2002], it is usually not ignored.

\subsection{Assumption That the Atmospheric Temperature} Response to a Reduction of $\mathrm{CO}_{2}$ Can Be Calculated by Assuming That the Temperature Will Respond With the Same Response Time as the Lifetime for $\mathrm{CO}_{2}$

[9] For the temperature response to $\mathrm{CO}_{2}\left(\right.$ or $\left.\mathrm{CH}_{4}\right)$, Jacobson [2002] does not solve equation (2), because the response time for atmospheric $\mathrm{CO}_{2}\left(\right.$ or $\left.\mathrm{CH}_{4}\right)$ concentrations to changes in emissions is of order 50 or 200 years (10 years for $\mathrm{CH}_{4}$ ) compared to the thermal response of the mixedlayer ocean (estimated here with a 100-m-deep mixed-layer ocean as 3.9 years). Thus Jacobson [2002] apparently estimates the time history of temperature response to a decrease in $\mathrm{CO}_{2}$ emissions from

$$
\frac{d T_{a}}{d t}=\frac{T_{e q}(t)-T}{\tau_{C O_{2}}},
$$

where $\tau_{\mathrm{CO} 2}$ is the atmospheric response time for the change in $\mathrm{CO}_{2}$ concentrations to changes in emissions.

[10] Jacobson [2002] uses the $\mathrm{CO}_{2}$ lifetime (taken as either 50 years or 200 years) to estimate the thermal response time to a decrease of all emissions of $\mathrm{CO}_{2}$. However, in calculating the response to a cessation of $\mathrm{CO}_{2}$ emissions, one needs to also consider the thermal response time of the atmosphere-ocean system.

[11] The solid gray curve in Figure 1 used the upwellingdiffusion ocean model to estimate the change in temperature associated with removing all emissions of $\mathrm{CO}_{2}$, assuming that $\mathrm{CO}_{2}$ concentrations relax to their preindustrial values $(275 \mathrm{ppm})$ with a response time of 50 years. The shortdashed gray curve solved equation (3) and assumed that the temperature, rather than the $\mathrm{CO}_{2}$ concentration, would relax to its preindustrial value with a response time of 50 years. As expected, using this last assumption results in a much faster predicted temperature response than that from the system that uses the full ocean model. My use of a 50-year lifetime is illustrative. Similar considerations would have applied had I used a $\mathrm{CO}_{2}$ response time of 200 years rather than 50 years.

[12] The ocean model used here has been "tuned" to yield a temperature change for $2 \times \mathrm{CO}_{2}$ (from $365 \mathrm{ppm}$ to $730 \mathrm{ppm}$ ) of $3.2^{\circ} \mathrm{C}$, to match as closely as possible the results from the Jacobson [2002] paper. However, the shortdashed gray curve in Figure 1 corresponding to a relaxation to preindustrial temperatures (which are about $1.3^{\circ} \mathrm{C}$ less than present-day temperatures) with a lifetime of 50 years does not replicate the corresponding curve from Jacobson [2002], which is shown as the long-dashed gray curve. This curve, instead, relaxes to a temperature change of $-0.9^{\circ} \mathrm{C}$. Apparently, Jacobson's [2002] model has a different climate sensitivity for the calculation of the temperature change associated with $2 \times \mathrm{CO}_{2}$ than for the calculation of the temperature change associated with the difference of present-day and preindustrial $\mathrm{CO}_{2}$ concentrations.

[13] This change in sensitivity may be real or may be the result of an insufficiently long calculation (see section 2.3). Several researchers have found changes in climate sensitivities associated with different forcings [Hansen et al., 1997;
Rotstayn and Penner, 2001; Hewitt et al., 2001], but I am not aware of any documented climate simulations with changes to the sensitivity of the model for different forcings associated with changes in $\mathrm{CO}_{2}$ up to $2 \times \mathrm{CO}_{2}$. If accurate, Jacobson's [2002] finding deserves explanation.

[14] If the climate sensitivity is assumed to be constant, then the scaling used by Jacobson [2002] clearly underestimates the response of atmospheric temperature to reductions in $\mathrm{CO}_{2}$. Incidentally, a present-day increase in temperatures from $\mathrm{CO}_{2}$ concentration increases of 1.3 degrees, when augmented by heating from other greenhouse gases, requires that a significant cooling mechanism also be acting in order to match the observed temperature change $\left(+0.6 \pm 0.2^{\circ}\right.$ [Intergovernmental Panel on Climate Change (IPCC), 2001]). This cooling is probably associated with aerosols and their indirect effects.

[15] IPCC has generally adopted a coupled carbon cycle model with the type of ocean model proposed by Hoffert et al. [1980] (i.e., one that includes thermal exchange of the mixed layer with a deep ocean) in determining the response of atmospheric temperatures to any given future forcing scenario [IPCC, 2001], though more recent IPCC model results utilize somewhat more elaborate formulations of upwellingdiffusion models [Wigley and Raper, 1990] than used here. A comparison of results from the upwelling-diffusion ocean model and the simpler models given by equations (2) and (3) shows the danger associated with only considering the simpler models. For the simpler model, there is a nearimmediate response to the decreased forcing from f.f. $\mathrm{BC}+$ $\mathrm{OM}$, and the temperature is at a near-equilibrium after 10 years (Jacobson [2002] obtains a "near equilibrium" after 5 years, but his mixed-layer model is only $60 \mathrm{~m}$ rather than $100 \mathrm{~m}$ as used here). For the upwelling-diffusion model, temperature responds much more gradually to both changes in f.f. $\mathrm{BC}+$ $\mathrm{OM}$ and changes in $\mathrm{CO}_{2}$ and $\mathrm{CH}_{4}$. Thus the benefits at any given point in time of reducing $\mathrm{BC}+\mathrm{OM}$ are clearly incorrect if Jacobson's [2002] model is used. For formulating the benefits of f.f. $\mathrm{BC}+\mathrm{OM}$ reduction as a function of time, a model that correctly accounts for mixing with the deep ocean and the coupling of the carbon cycle lifetime with this response time must be used.

[16] Jacobson [2002] uses his calculations to argue that replacement of gasoline-fueled automobiles with dieselfueled automobiles would not contribute to cooling climate. If the current simulations are correct (i.e., if current f.f. BC + OM emissions warm by of order $0.5 \mathrm{Wm}^{-2}$ ), then Jacobson's [2002] conclusions remain valid in general, though the specific timescales over which a given emission level for f.f. $\mathrm{BC}+\mathrm{OM}$ contributes to warming do not hold because of the neglect of mixing with the deep ocean. Section 2.4 examines whether or not f.f. $\mathrm{BC}+\mathrm{OM}$ emissions warm the climate as much as Jacobson [2002] predicts.

\subsection{Assumption That the Steady State Results of the Climate Model Can Be Calculated With Calculations of Only 6 Years' Duration}

[17] The response time for a climate model is actually longer than the mixed-layer response time, especially one with high climate sensitivity. Hansen et al. [1984] showed that the isolated mixed-layer response time (i.e., the response time ignoring exchange of heat with the deep ocean) was 10-20 years for a model with an average 
mixed-layer depth of $63 \mathrm{~m}$ and a climate sensitivity of $4^{\circ} \mathrm{C}$. For a climate sensitivity of $3.2^{\circ} \mathrm{C}$ as given by Jacobson [2002], this $e$-folding timescale might decrease to $8-$ 16 years. Thus it is dangerous to run the model for only 6 years to calculate either the quasi-steady state control climate, the preindustrial climate, or the response to doubling of $\mathrm{CO}_{2}$, as did Jacobson [2002]. Moreover, models that have been run for longer time periods show that even a 20 -year calculation may not be adequate. Figure 1 of Hansen et al. [1988] shows the global mean surface temperature for a 100 -year control run for his model with a $125-\mathrm{m}$ maximum mixed-layer depth. Variations of order $0.4^{\circ} \mathrm{C}$ occur over a 20-year period near the middle of the simulation, but the first 20 years of simulation appear to be reasonably constant. Manabe and Stouffer [1996] show similar long-term trends in their unforced mixed-layer model simulations. Barnett et al. [1992] analyzed the reasons for the long timescale variability in the Hansen et al. [1988] model. It is associated with latitudinal variations in mixed-layer temperatures that produce variations in the model's precipitation and cloud cover over time.

[18] The timescales for these latter variations are of order 5 times the timescales associated with the mixed-layer response time. Thus, if the mixed-layer response time in Jacobson's [2002] model is assumed to be 5-10 years, and longer timescales may be associated with the interactions of clouds with sea surface temperatures that are of the same order as that observed in the Hansen et al. [1988] model, then Jacobson's [2002] model might exhibit long-term variations of order 25 years or more. With such stochastic variability, one can clearly not choose any given 6-year period and hope to assume that the model is in quasi-steady state.

[19] What is the consequence of failing to make sure that the model has reached equilibrium? Again, the failure affects the time history of temperature response that Jacobson [2002] reports. If the climate sensitivity in his model is actually $4.5^{\circ} \mathrm{C}$ for $2 \times \mathrm{CO}_{2}$, one would expect a faster response to both $\mathrm{CO}_{2}$ and $\mathrm{BC}+\mathrm{OM}$ reductions. Likewise, if the climate sensitivity of his model is less than $3.2^{\circ} \mathrm{C}$, one would expect a more sluggish response.

\subsection{Assumption That the Net Effects of f.f. $\mathrm{BC}+\mathrm{OM}$ Emissions Warm the Climate}

[20] Jacobson's [2002] main result, i.e., that reductions of f.f. $\mathrm{BC}+\mathrm{OM}$ would lead to cooling, hangs on the conclusion that f.f. $\mathrm{BC}+\mathrm{OM}$ emissions warm surface temperatures. This result is partly suspect if, as noted above, the model has not been run to equilibrium and a valid average surface temperature difference has not been found.

[21] However, is a net warming by f.f. $\mathrm{BC}+\mathrm{OM}$ an expected result? The paper by Jacobson [2002] includes both the direct effects of f.f. $\mathrm{BC}+\mathrm{OM}$ and the indirect effects of f.f. $\mathrm{BC}+\mathrm{OM}$ due to their effects on clouds. Two models have addressed this issue (though neither has all the bells and whistles of the Jacobson [2002] calculation). Lohmann and Feichter [2001] calculated the direct and indirect forcing associated with the combined effects of anthropogenic sulfate, fossil-fuel $\mathrm{BC}+\mathrm{OM}$, and biomass smoke. Both the first indirect forcing (i.e., the effect of aerosols on droplet number) and the second indirect forcing (i.e., the effect of aerosols on cloud microphysics and the precipitation efficiency) were considered. Earlier simulations by these authors showed that these two effects were roughly equal in magnitude [Lohmann et al., 2000]. The combined direct plus indirect shortwave forcing from sulfate, fossil-fuel $\mathrm{BC}+\mathrm{OM}$, and biomass smoke was $-1.3 \mathrm{Wm}^{-2}$ in columns where the $\mathrm{BC}$ burden exceeded $2 \mathrm{mg} \mathrm{m}{ }^{-2}$. Penner et al. [2003] consider only the first indirect effect together with the direct effect, but they separate the forcing by fossil-fuel $\mathrm{BC}+\mathrm{OM}$ and that from biomass smoke from the combination of sulfate, fossil-fuel $\mathrm{BC}+\mathrm{OM}$, and biomass smoke.

[22] Penner et al. [2003] consider both the shortwave and longwave effects of these aerosols using both a strict calculation of the instantaneous forcing and a calculation of "relaxed-" or "quasi-" forcing (which is the difference between two sets of 10-year calculations with fixed seasurface temperatures [see Rotstayn and Penner, 2001]). Researchers have routinely used a relaxed-forcing calculation to quantify changes in radiative fluxes when changes in clouds are computed (as in the second indirect effect). Rotstayn and Penner [2001] showed that a calculation of relaxed-forcing appeared to be a good indicator of the global average surface temperature change for the first and second indirect effects of anthropogenic sulfate aerosols.

[23] Penner et al. [2003] find a global average relaxedforcing of $+0.08 \mathrm{Wm}^{-2}$ and $+0.01 \mathrm{Wm}^{-2}$ for direct and direct + indirect effects of fossil-fuel $\mathrm{BC}+\mathrm{OM}$, respectively. Neither result is significantly different from zero at the 5\% confidence level. The shortwave direct + first indirect effect for the Penner et al. model may be an overestimate (too negative) since it is about twice the size of the shortwave effect in the model of Lohmann et al. [2000], if we assume that the first indirect effect in the model of Lohmann and Feichter [2001] is roughly half the size of the total first + second indirect effects [Lohmann et al., 2000]. Nevertheless, the absolute magnitude of forcing in these two models is similar.

[24] Thus Penner et al. [2003] derive a globally averaged shortwave relaxed-forcing of $-1.18 \mathrm{Wm}^{-2}$ from the direct plus the first indirect effect for biomass + fossil-fuel $\mathrm{BC}+$ OM while Lohmann et al. [2000] derive a difference in the shortwave cloud forcing for a similar perturbation of $-0.9 \mathrm{Wm}^{-2}$ for the first and second indirect effects combined when calculated as an internal mixture or of $-1.3 \mathrm{Wm}^{-2}$ when calculated as an external mixture. Thus the results from Jacobson [2002] do not appear to be consistent with the results of these published models since Jacobson's [2002] warming implies a strong positive forcing of about $0.5 \mathrm{Wm}^{-2}$ (as derived above) for the direct and indirect effects of fossil-fuel $\mathrm{BC}+\mathrm{OM}$.

[25] It does not appear that Jacobson [2002] includes the second indirect effect (i.e., the effect of aerosols on cloud microphysics), since he states that the precipitation-formation mechanism in his model is that in the original University of California, Los Angeles, general circulation model (UCLA GCM) for stratus clouds and that given by Ding and Randall [1998] for convective precipitation. Thus his cloud indirect effects, which should lead to more cooling, may be underestimated relative to other models that include the second indirect effect.

[26] What is the magnitude of the first (or first plus second) indirect forcing in the model of Jacobson [2002]? 
Unfortunately, he explains that such quantities are difficult to provide, since it requires turning off all the built-in interactions in his model (and would require 2 radiation calls to calculate as an instantaneous forcing), so we have no way to know.

[27] One might suspect that Jacobson [2002] obtains a fairly small indirect cloud effect in his model, but the method used to calculate cloud microphysical changes is not described. (Hence my statement that the model is inadequately documented.) The number of aerosols that act as $\mathrm{CCN}$ in any given situation depends on the vertical velocity in cloud updrafts which acts to force higher water vapor supersaturations. Jacobson [2002] refers to a paper in 1997 for the method he uses to calculate the condensational growth of water on aerosol particles, but that paper neglects any discussion of how he treats the vertical velocity in cloud updrafts [Jacobson, 1997]. If he used the GCM vertical velocity to directly calculate supersaturation, he could severely underestimate droplet number because the largescale vertical velocity is much smaller than the vertical velocity in cloud updrafts. Other models have parameterized this aspect, using either the predicted turbulent kinetic energy [e.g., Lohmann et al., 1999] or using observed ranges of cloud-scale updrafts and relating these to the large-scale vertical velocity [Chuang et al., 2002].

[28] Finally, we note that Jacobson [2002, Figure 11] shows that cloud optical depths are increased in his model, but, of course, these increases are not simply due to the change in aerosol concentration because they include the change in the full temperature response (including the ocean response) as well as the initial microphysical changes induced by aerosols. Figure 11 in Jacobson's [2002] paper clearly demonstrates that this field is dominated by dynamical effects rather than microphysical effects associated with aerosols because the largest changes are not in the regions with the largest changes in f.f. $\mathrm{BC}+\mathrm{OM}$.

[29] In sum, the magnitude of cloud indirect effect in Jacobson's [2002] model may well be considerably smaller (less negative) than that in the model of Penner et al. [2003], implying that the total direct + indirect relaxedforcing and perhaps even the instantaneous forcing is positive in his model rather than near zero or negative as in other models. Jacobson [2002] claims that a myriad of additional indirect effects in his model could explain his warming results for f.f. $\mathrm{BC}+\mathrm{OM}$; however, he does not demonstrate their importance relative to the cloud indirect effects that have been the main focus of most research to date. As other models weigh in on their calculations of the direct and indirect effects of f.f. $\mathrm{BC}+\mathrm{OM}$, we may obtain a clearer indication of whether Jacobson's [2002] calculation is consistent with these or not.

[30] What is the consequence of an inaccurate assessment of the forcing due to f.f. $\mathrm{BC}+\mathrm{OM}$ ? If the results of the model of Penner et al. [2003] or, by inference, the model of Lohmann et al. [2000] are correct, then reductions of f.f. $\mathrm{BC}+\mathrm{OM}$ would have almost no climate effect in Figure 1. Such results should also be considered until a better understanding of the both the direct and indirect forcing by f.f. $\mathrm{BC}+\mathrm{OM}$ is available [Hansen et al., 2000].

\section{References}

Barnett, T. P., A. D. Del Genio, and R. Ruedy, Unforced decadal fluctuations in a coupled model of the atmosphere and ocean mixed layer, J. Geophys. Res., 97, 7341-7354, 1992.

Burt, J. E., and J. A. Viecelli, Magnitude of ocean termperature feedback effects in a coupled carbon budget-energy balance model for the period 1800-2100, Clim. Change, 2(3), 267-274, 1980.

Chuang, C. C., J. E. Penner, K. E. Grant, J. M. Prospero, G. H. Rau, and K. Kawamoto, Cloud susceptibility and the first aerosol indirect forcing: Sensitivity to black carbon and aerosol concentrations, J. Geophys. Res., 107(D21), 4564, doi:10.1029/2000JD000215, 2002

Ding, P., and D. A. Randall, A cumulus parameterization with multiple cloud-base levels, J. Geophys. Res., 103, 11,341-11,353, 1998.

Forest, C. E., P. H. Stone, A. P. Sokolov, M. R. Allen, and M. D. Webster, Quantifying uncertainties in climate system properties with the use of recent climate observations, Science, 295, 113-117, 2002.

Hansen, J., A. Lacis, D. Rind, G. Russell, P. Stone, I. Fung, R. Ruedy, and J. Lerner, Climate sensitivity: Analysis of feedback mechanisms, in Climate Processes and Climate Sensitivity, edited by J. E. Hansen, and T. Takahashi, pp. 130-163, AGU, Washington, D. C., 1984.

Hansen, J., G. Russell, A. Lacis, I. Fung, D. Rind, and P. Stone, Climate response times: Dependence on climate sensitivity and ocean mixing, Science, 229, 857-859, 1985

Hansen, J., I. Fung, A. Lacis, D. Rind, S. Lebedeff, R. Ruedy, and G. Russell, Global climate changes as forecast by Goddard Institute for Space Studies three-dimensional model, J. Geophys. Res., 93, 93419364, 1988.

Hansen, J., M. Sato, and R. Ruedy, Radiative forcing and climate response, J. Geophys. Res., 102, 6831-6864, 1997.

Hansen, J., M. Sato, R. Ruedy, A. Lacis, and V. Oinas, Global warming in the twenty-first century: An alternative scenario, Proc. Natl. Acad. Sci. U. S. A., 97, 9875-9880, 2000.

Hewitt, C. D., C. A. Senior, and J. F. B. Mitchell, The impact of dynamic sea-ice on the climatology and climate sensitivity of a GCM: A study of past, present, and future climates, Clim. Dyn., 17, 655-668, 2001.

Hoffert, M. I., A. J. Callegari, and C.-T. Hsieh, The role of deep sea heat storage in the secular response to climatic forcing, J. Geophys. Res., 85, 6667-6679, 1980.

Intergovernmental Panel on Climate Change (IPCC), Climate Change 2001: The Scientific Basis, Report to Intergovernmental Panel on Climate Change From the Scientific Assessment Working Group (WGI), edited by H. T. Houghton et al., Cambridge Univ. Press., New York, 2001.

Jacobson, M. Z., Numerical techniques to solve condensational and dissolutional growth equations when growth is coupled to reversible reactions, Aerosol Sci. Technol., 27, 491-498, 1997.

Jacobson, M. Z., Control of fossil-fuel particulate black carbon and organic matter, possibly the most effective method of slowing global warming, J. Geophys. Res., 107(D19), 4410, doi:10.1029/2001JD002044, 2002.

Lohmann, U., and J. Feichter, Can the direct and semi-direct aerosol effect compete with the indirect effect on a global scale?, Geophys. Res. Lett., $28,159-161,2001$

Lohmann, U., J. Feichter, C. C. Chuang, and J. E. Penner, Prediction of the number of cloud droplets in the ECHAM GCM, J. Geophys. Res., 104, 9169-9198, 1999

Lohmann, U., J. Feichter, J. E. Penner, and R. Leaitch, Indirect effect of sulfate and carbonaceous aerosols: A mechanistic treatment, J. Geophys. Res., 105, 12,193-12,206, 2000.

Manabe, S., and R. J. Stouffer, Low-frequency variability of surface air temperature in a 1000-year integration of a coupled atmosphere-oceanland surface model, J. Clim., 9, 376-393, 1996.

Penner, J. E., S. Y. Zhang, and C. C. Chuang, Soot and smoke aerosol may not warm climate, J. Geophys. Res., 108(D21), 4657, doi:10.1029/ 2003JD003409, 2003.

Rotstayn, L. D., and J. E. Penner, Forcing, quasi-forcing and climate response, J. Clim., 14, 2960-2975, 2001.

Schneider, S. H., and C. Mass, Volcanic dust, sunspots, and temperature trends, Science, 190, 741-746, 1975.

Wigley, T. M. L., and S. C. B. Raper, Natural variability of the climate system and detection of the greenhouse effect, Nature, 34, 324-327, 1990.

J. E. Penner, Department of Atmospheric, Oceanic, and Space Sciences, University of Michigan, 2455 Hayward, Ann Arbor, MI 48109-1349, USA. (penner@umich.edu) 